\title{
In vitro and in vivo evaluation of cord blood hematopoietic stem and progenitor cells amplified with glycosaminoglycan mimetic
}

Lionel Faivre ${ }^{1,2}$, Véronique Parietti ${ }^{3}$, Fernando Siñeriz $^{4}$, Sandrine Chantepie ${ }^{5}$, Marie Gilbert-Sirieix ${ }^{4}$, Patricia Albanese ${ }^{5}$, Jérôme Larghero ${ }^{1,2,6}$ and Valérie Vanneaux ${ }^{1,2^{*}}$

\begin{abstract}
Background: Expansion protocols aim at both increasing the number of umbilical cord blood (UCB) hematopoietic stem cells and progenitor cells (HSPCs) and reducing the period of neutropenia in UCB HSPC graft. Because glycosaminoglycans (GAGs) are known to be important components of the hematopoietic niche and to modulate growth factor effects, we explored the use of GAG mimetic OTR4131 to potentiate HSPC's in vitro expansion and in vivo engraftment.

Methods: UCB CD34+ cells were expanded with serum-free medium, SCF, TPO, FLT3-lig and G-CSF during 12 days in the absence or the presence of increasing OTR4131 concentrations $(0-100 \mu \mathrm{g} / \mathrm{mL})$. Proliferation ratio, cell viability and phenotype, functional assays, migration capacity and NOD-scid/ $/ \mathrm{C}^{-1-}$ mice engraftment were assessed after expansion.

Results: At Day 12, ratios of cell expansion were not significantly increased by OTR4131 treatment. Better total nucleated cell viability was observed with the use of $1 \mu \mathrm{g} / \mathrm{mL}$ GAG mimetic compared to control $(89.6 \% \pm 3.7 \%$ and $79.9 \% \pm 3.3 \%$, respectively). Phenotype analysis showed a decrease of monocyte lineage in the presence of OTR4131 and HSPC migration capacity was diminished when GAG mimetic was used at $10 \mu \mathrm{g} / \mathrm{mL}(10.9 \% \pm 4.1 \%$ vs. $52.9 \% \pm 17.9 \%$ for control). HSPC clonogenic capacities were similar whatever the culture conditions. Finally, in vivo experiments revealed that mice successfully engrafted in all conditions, even if some differences were observed during the first month. Three months after graft, bone marrow chimerism and blood subpopulations were similar in both groups.

Conclusions: UCB HSPCs ex-vivo expansion in the presence of OTR4131 is a safe approach that did not modify cell function and engraftment capacities. In our experimental conditions, the use of a GAG mimetic did not, however, allow increasing cell expansion or optimizing their in vivo engraftment.
\end{abstract}

Keywords: Hematopoietic stem cells, Expansion, Cord blood, Heparan sulfate, Glycosaminoglycan mimetic

\footnotetext{
*Correspondence: valerie.vanneaux@aphp.fr

'Inserm, U 1160, Centre d'Investigation Clinique en Biothérapies, 75010 Paris,

France

${ }^{2}$ AP-HP, Hôpital Saint-Louis, Unité de Thérapie Cellulaire, Paris F-75010,

France

Full list of author information is available at the end of the article
} 


\section{Background}

Umbilical cord blood (UCB) is an alternate source of both hematopoietic stem cells and progenitor cells (HSPCs) that is used to treat patients with hematologic diseases. Despite numerous advantages of UCB, such as easy access and lack of ethical issues, UCB HSPC transplantation has been hampered by the lower HSPC number compared with that in bone marrow or peripheral blood stem cells, leading to a longer period of posttransplant neutropenia and a delayed immunological reconstitution [1]. To overcome the limitation of cell quantity and maturity, many strategies have been proposed and developed to expand UCB HSPCs ex vivo and optimize the UCB transplantation process [2]. The advanced understanding of HSPC biology induced the development of numerous ex vivo amplification protocols based on growth factors and cocultivation. Using hematopoietic specific cytokines was the first and easiest method to amplify HSPCs [3, 4]. Based on this, we used a serum-free ex vivo culture protocol involving a cocktail of four selected cytokines (SCF, TPO, FLT3-lig, and granulocyte colony-stimulating factor (G-CSF)) developed by the Dazey laboratory and currently evaluated in clinical trials (NCT01034449), which have already demonstrated in vitro and in vivo relevant results [5]. An important milestone of such amplification protocols is not only to increase the amount of cells but also their survival quality, in order to optimize their in vivo engraftment in the medullary compartment.

The bone marrow stem cell niche is a complex structure, composed of cells, cytokines, and extracellular matrix (ECM) whose glycosaminoglycans (GAGs) are known to play an important role both in spatial organization and in interaction with cells and hematopoietic cytokines [6, 7]. In this site, the major GAGs are heparan sulfate (HS) and chondroitin sulfate (CS) [8]. Their use in ex vivo HSPC amplification protocols could participate in a better amplification process in terms of cell quality and quantity. Indeed, HS and CS are long polysaccharides composed of specific disaccharide building blocks, characterized by complex structures due to heterogeneity in glucosidic linkages, hydrophobic regions, and sulfatation patterns [9]. All properties of HS define the anionic interaction and hydrogen binding protein. Thus, HS could constitute a low-affinity receptor to heparin-binding proteins which could be necessary for signal transduction, such as described previously for syndecans on hematopoietic progenitor cells [10].

Owing to these properties, a family of chemicallyengineered analogs of endogenous GAGs has been developed, named ReGeneraTing Agents (RGTA; OTR3 SARL, Paris, France) [11, 12]. GAG mimetic syntheses are performed according to Good Manufacturing Practice grade, an essential point in human clinical issues. It was recently demonstrated that a specific GAG mimetic, namely OTR4131, is able to potentiate properties of different stem and progenitor cells: injection of this mimetic into mice was associated with mobilization of hematopoietic stem cells (HSCs) from the bone marrow to peripheral blood, according to an in vivo modification of the SDF-1 gradient [13].

According to the functional relevance of these GAG/ cytokine interactions in HSPC homeostasis regulation, we investigated in the present study whether the association of a GAG mimetic could optimize the in vitro clinical UCB-derived HSPC amplification procedure. Moreover, whereas HSPC graft with intensive therapies (chemotherapy and/or total body irradiation) induced bone marrow lesions [14], we tested whether the presence of GAG mimetics during the UCB-derived HSPC expansion step could optimize the UCB HSPC in vivo engraftment.

\section{Methods \\ HSPC purification, cryopreservation, and thawing}

UCB units from normal full-term deliveries were obtained from Saint-Louis Hospital Cord Blood Bank (Paris, France) after mothers' written informed consent, in accordance with health authorities (French Cord Blood Network, Paris, France). The study was approved by the Saint-Louis Hospital Biological Resource Center Scientific Council (authorized by the French Ministry of Research under number AC-2008-376). Mononuclear cells were separated with lymphocyte separation medium (Eurobio, Courtaboeuf, France). CD34+ HSPCs were isolated by supermagnetic microbead with a QuadroMAC Separator (Miltenyi Biotech, Paris, France) according to the manufacturer's instructions. CD34 purified cells were kept frozen in liquid nitrogen and thawed on the day of amplification.

\section{RGTA ${ }^{\oplus}-$ OTR4131}

RGTA-OTR4131 mimetic was obtained from OTR3 SARL. RGTA -OTR4131 is a dextran derivative, composed of about 250 glucosidic units, with carboxylate and sulfate degrees of substitution close to those of heparin, except for a lower degree of the acetyl group [11, 12]. When needed, OTR4131 was coupled with the fluorescent dye Alexa Fluor $647^{\circ}$ (AF ${ }^{647}$-OTR4131) and image acquisition was made with Nikon BioStation IM (Nikon, Champigny sur Marne, France). OTR4131 compound was used during HSPC expansion at concentrations ranging from 0 to $100 \mu \mathrm{g} / \mathrm{ml}$.

\section{Expansion protocol}

Complete medium was composed of serum-free HP01 culture medium (Macopharma, Tourcoing, France) containing 100 ng/ml SCF, 20 ng/ml TPO, 100 ng/ml FLT3Lig (all provided by Peprotech, Neuilly sur Seine, France), and $10 \mathrm{ng} / \mathrm{ml}$ Filgrastim (Zarzio; Sandoz, 
Table 1 Details of CD used for each cell population described

\begin{tabular}{|c|c|c|c|}
\hline & Population & Panel & Percentage expressed in \\
\hline \multirow{11}{*}{ In vitro analysis } & Enriched HSC & CD45/34/90 & CD45 \\
\hline & Myeloid progenitor & $\mathrm{CD} 45 / 34^{\mathrm{hi}} / 33$ & Cells \\
\hline & Myeloid precursor & $\mathrm{CD} 45 / 34^{\mathrm{lo}} / 33$ & Cells \\
\hline & Monocyte lineage & $\mathrm{CD} 45 / 34^{-} / 33 / 14$ & Cells \\
\hline & Neutrophil lineage & $\mathrm{CD} 45 / 34^{-} / 14^{-} / 33$ & Cells \\
\hline & B-lymphocyte progenitor & CD45/34/10/19 & CD45 \\
\hline & B-lymphocyte lineage & CD45/10/19 & CD45 \\
\hline & Megakaryocyte precursor & CD45/34/41/42 & Cells \\
\hline & Immature platelet & CD45/41/42 & Cells \\
\hline & Erythroid lineage & CD45/36/235a & Cells \\
\hline & Immature erythrocyte & $\mathrm{CD} 45^{-} / 36 / 235 \mathrm{a}$ & Cells \\
\hline \multirow{21}{*}{ Mice analysis } & Hematopoietic cells & CD45 & Cells \\
\hline & HSPCS & CD45/34 & CD45 \\
\hline & Enriched HSC & CD45/34 hi & CD45 \\
\hline & HSC & CD45/34/38 $/ 90 / 45 \mathrm{RA}^{-}$ & CD34 \\
\hline & MPP & $\mathrm{CD} 45 / 34 / 38^{-} / 90^{-} / 45 \mathrm{RA}^{-}$ & CD34 \\
\hline & CLP & CD45/34/10 & CD34 \\
\hline & GMP & CD45/34/10-/38/135/45RA & CD34 \\
\hline & CMP & $\mathrm{CD} 45 / 34 / 10^{-} / 38 / 135 / 45 \mathrm{RA}^{-}$ & CD34 \\
\hline & MEP & CD45/34/10-/38/135-/45RA & CD34 \\
\hline & T-lymphocyte progenitor & $\mathrm{CD} 45 / 34 / 10^{-} / 19^{-} / 7$ & CD34 \\
\hline & B-lymphocyte progenitor & CD45/34/10/19/7 & CD34 \\
\hline & B-lymphocyte & CD45/34-/19/7 & CD45 \\
\hline & Myeloid progenitor & $\mathrm{CD} 45 / 34^{\mathrm{hi}} / 33$ & CD34 \\
\hline & Myeloid precursor & $\mathrm{CD} 45 / 34^{\mathrm{lo}} / 33 / 15$ & CD34 \\
\hline & Dendritic cell & $\mathrm{CD} 45 / 34^{-} / 14 / 15^{-} / 11 \mathrm{~b} / 11 \mathrm{c}$ & CD45 \\
\hline & Monocyte & $\mathrm{CD} 45 / 34^{-} / 33 / 14 / 15^{-}$ & CD45 \\
\hline & Neutrophil & $\mathrm{CD} 45 / 34^{-} / 33 / 14^{-} / 15$ & CD45 \\
\hline & Megakaryocyte precursor & CD45/34/41a/42 & CD45 \\
\hline & Platelet & $\mathrm{CD} 45^{-} / 41 \mathrm{a} / 42$ & Cells \\
\hline & Erythroid lineage & CD45/36/235a & CD45 \\
\hline & Erythrocyte & $\mathrm{CD} 45^{-} / 235 \mathrm{a}$ & Cells \\
\hline
\end{tabular}

CD cluster of differentiation, CLP common lymphoid progenitor cells, CMP common myeloid progenitor cells, GMP granulocyte macrophage progenitor cells, hi high, HSC hematopoietic stem cells, HSPC hematopoietic stem cell and progenitor cell, lo low, MEP megakaryocyte erythroid progenitor cells, MPP multipotent progenitor cells

Levallois-Perret, France), as described previously [15]. HSPC expansion was initiated by culturing $20 \times 10^{3}$ $\mathrm{CD} 45^{+} / 34^{+}$viable purified cells per milliliter in complete medium at $5 \% \mathrm{CO}_{2}$ in water-saturated air for 6 days in 24-well plates. Cultured cells were then transferred into six-well plates (all from Becton Dickinson, Le Pont De Claix, France) for another 6 days, with fresh complete medium $(4 / 1 \mathrm{v} / \mathrm{v})$. Cell phenotype was performed at day 12 by flow cytometry analysis according to the antigen panel presented in Table 1. Cell expansion was expressed as the ratio between absolute cell numbers at day $12 \mathrm{di}-$ vided by absolute cell numbers at day 0 .

\section{Flow cytometry analysis}

Cells were washed in phosphate-buffered saline and incubated for 30 minutes at $4{ }^{\circ} \mathrm{C}$ with a combination of monoclonal antibodies against human cell surface antigens as presented in Table 1. Antibodies were purchased 
as described: CD36 APC, CD14 PE-Cy7, CD42 PE, CD33 PE, CD34 APC, CD45 FITC (all from Becton Dickinson), CD34 Pacific Blue, CD45 Alexa Fluor 700, CD41 APC, CD90 APC, CD10 PE-Cy7, CD19 PE-Cy7 (all from Biolegend, Saint Quentin en Yvelines, France), and CD235a PE, 7-AAD (both from Beckmann Coulter, Villepinte, France). Cells were analyzed on a FACSCanto II flow cytometer (Becton Dickinson) using Diva software (version 6.1.3; Becton Dickinson).

\section{Migration assay}

The migration assay was performed in 24-well culture plates with a $5 \mu \mathrm{m}$ pore size Transwell (Corning, Tewksbury, Massachusetts, USA). SDF- $1 \alpha(100 \mathrm{ng} / \mathrm{ml} ; \mathrm{R} \& D$ Systems, Lille, France) was added to the lower chamber. Then $1 \times 10^{5}$ cells per well, washed beforehand, were placed in the upper compartment and incubated at $37^{\circ}$ $\mathrm{C}$ and $5 \% \mathrm{CO}_{2}$. The percentage of cell migration was calculated after 6 hours.

\section{Colony-forming unit quantification}

Clonogenicity of expanded cells was assessed by methylcellulose-based semisolid cultures according to the manufacturer's protocol (MethoCult ${ }^{\circ}$; StemCell Technologies, Grenoble, France). Viable CD $34^{+} / \mathrm{CD} 45^{+}$ cells were seeded in duplicate in six-well culture plates at 300 cells $/ \mathrm{ml}$. Cells were incubated at $37{ }^{\circ} \mathrm{C}$ and $5 \%$ $\mathrm{CO}_{2}$ and colony-forming units (CFUs) were scored using an inverted microscope after 14 days. Hematopoietic colonies were identified as follows: colonies containing both erythroid and myeloid cells (CFU-GEMM); colonies containing erythroid cells (CFU-E); myeloid colonies of pure granulocytic colonies (CFU-G); monocytic colonies (CFU-M); and colonies containing both granulocytes and monocytes (CFU-GM). Results were expressed as the CFU number per $1000 \mathrm{CD} 34^{+} / \mathrm{CD} 45^{+}$ cells.

\section{Animal model}

Immunodeficient NOD-scid/ $/ \mathrm{c}^{-/-}$(NSG) mice (The Jackson Laboratory, Bar Harbor, Maine, USA) were bred and maintained in strict accordance with Directive 2010/63/UE. The protocol was approved by the Committee on the Ethics of Animal Experiments of the French Ministry of Agriculture (Permit Number: 02447.01). Eight-week old mice were irradiated with 2.25 Gy 24 hours before intravenous injection of $1 \times 10^{6}$ cells expanded in the presence or absence of $1 \mu \mathrm{g} / \mathrm{ml}$ OTR4131, according to the protocol already described. The bone marrow, spleen, and thymus were harvested 1 and 3 months later, flushed, and crushed on a $100 \mu \mathrm{m}$ strainer before flow cytometer analysis $(n=4$ mice per time point) of different subsets of the hematopoietic population according to clusters of differentiation, as presented in Table 1. Chimerism was evaluated by the percentage of human $\mathrm{CD} 45^{+}$cells in different organs.

\section{Statistical analysis}

Data are expressed as the mean \pm standard deviation. Mean value comparisons were assessed by a $t$ test on paired samples. All calculations were performed using MedCalc $^{\circ}$ (version 7.2.1.0; MedCalc Software, Ostend, Belgium). The reported $p$ values are two-sided and significance was defined as $p<0.05$.

\section{Results}

\section{In vitro evaluation of expanded HSPCs}

We first aimed at evaluating how GAG mimetic interacts with HSPCs. To this aim, $10 \mu \mathrm{g} / \mathrm{ml} \mathrm{AF}^{647}$-OTR4131 was added to culture medium, and fluorescence was evaluated at days $3,6,9$, and 12 . AF ${ }^{647}$-OTR4131 fluorescent compound was shown to interact with HSPCs, and was found on the surface and in the cytoplasm of HSPCs whatever the time point considered. Intracellular staining was found to increase with time (Fig. 1a-d).

Purified UCB HSPC expansion was then performed, following a 12 -day process. $\mathrm{CD} 34^{+} / \mathrm{CD} 45^{+}$cell purity and viability before culture were $88.1 \pm 7.7 \%$ and $96.0 \pm$ $1.9 \%$, respectively $(n=9)$. At day 12 the amplification ratios of total nucleated cells (TNC) and of CD34 ${ }^{+} / \mathrm{CD} 45^{+}$cells were evaluated in the absence or the presence of increasing OTR4131 concentrations (from $1 \mathrm{ng}$ / $\mathrm{ml}$ to $100 \mu \mathrm{g} / \mathrm{ml}$ ). The mean TNC expansion ratio was $390.0 \pm 147.1$ for control, and ranged from 401.0 to 549.2 in the presence of OTR4131 ( $p>0.05$ for all conditions). At the $\mathrm{CD} 34^{+} / \mathrm{CD} 45^{+}$level, expansion in complete medium was $49.0 \pm 28.3$ at day 12 , and between 45.7 and 55.1 at the tested OTR4131 concentrations $(p>0.05$, Fig. 1e).

After 6 days of expansion, $\mathrm{TNC}$ or $\mathrm{CD} 34^{+} / \mathrm{CD} 45^{+}$cell viabilities were similar whatever the conditions. However, a higher TNC viability was obtained in the presence of $1 \mu \mathrm{g} / \mathrm{ml}$ OTR4131 after 12 days of expansion, with $89.6 \pm 3.7 \%$ compared with $79.9 \pm 3.3 \%$ in control conditions $(p=0.0024)$. CD $34^{+} / \mathrm{CD} 45^{+}$viability followed the same trend in the presence of OTR4131, while not reaching significant statistical difference (Fig. 1f).

In order to determine the impact of OTR4131 on the outcome of cell phenotype during the amplification phase, cell phenotypes were analyzed after 12 days of expansion. Results are summarized in Fig. 2. The percentage of $\mathrm{CD}_{3} 4^{+} / \mathrm{CD} 45^{+}$HSPCs was $14.1 \pm 11.4 \%$ in control conditions, and ranged from 5.6 to $31.3 \%$ in the presence of OTR4131 ( $p>0.05$ for all tested conditions). Within the $\mathrm{CD} 34^{+} / \mathrm{CD} 45^{+}$cell population, the number of more immature $\mathrm{CD} 34^{+} / \mathrm{CD} 45^{+} / \mathrm{CD} 90^{+}$HSCs was also similar in the presence or absence of OTR4131 during the expansion protocol. Analysis of the committed 


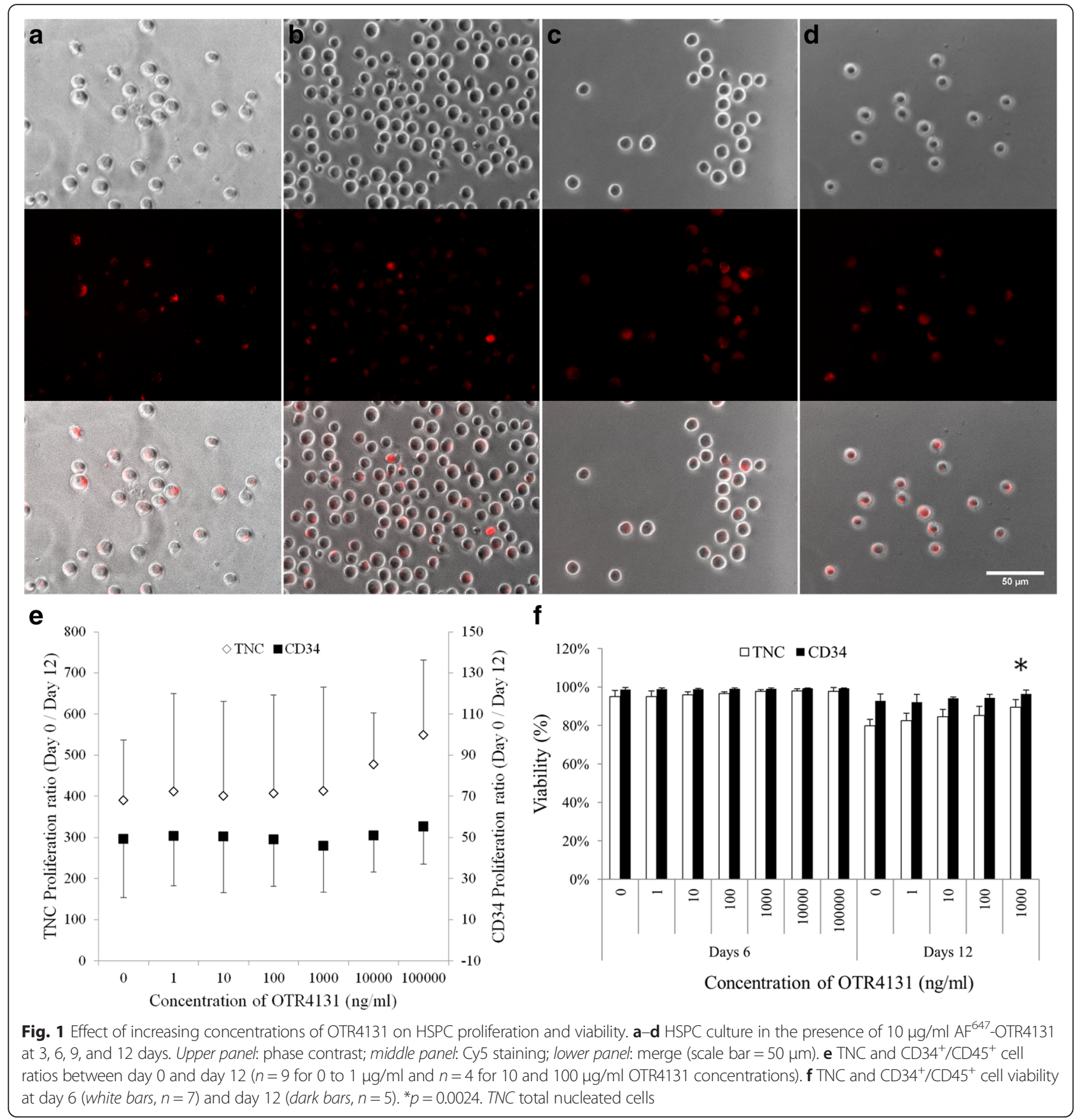

myeloid subpopulations showed that only the monocyte percentage decreased in the presence of $100 \mu \mathrm{g} / \mathrm{ml}$ OTR4131 compared with control $(35.1 \pm 6.3 \%$ vs. $26.3 \pm 2.7 \%, p=0.04)$. The lymphoid lineage was not significantly modified whatever the experimental conditions, even if a slight decrease of B-lymphoid progenitors was observed with $10 \mu \mathrm{g} / \mathrm{ml}$ OTR4131. Platelet and erythroid lineages were also not affected.

HSPC clonogenic capacities were also assessed at the end of the expansion protocol. After 14 days of semisolid culture of 1000 viable $\mathrm{CD} 34^{+} / \mathrm{CD} 45^{+}$cells, the numbers of CFU-G, CFU-M, CFU-GM, CFU-E, and CFU-GEMM were not significantly different between control and increasing OTR4131 concentration (Fig. 3a), thus suggesting that HSC expansion in the presence of GAG mimetic does not affect HSPC differentiation properties.

Interestingly, high OTR4131 concentrations were shown to diminish cell migration capacities toward the SDF-1 gradient. At 10 and $100 \mu \mathrm{g} / \mathrm{ml}$ OTR4131, the percentages of migration were $10.9 \pm 4.1 \%$ and $13.7 \pm$ $12.9 \%$, respectively, compared with $52.9 \pm 17.9 \%$ for 


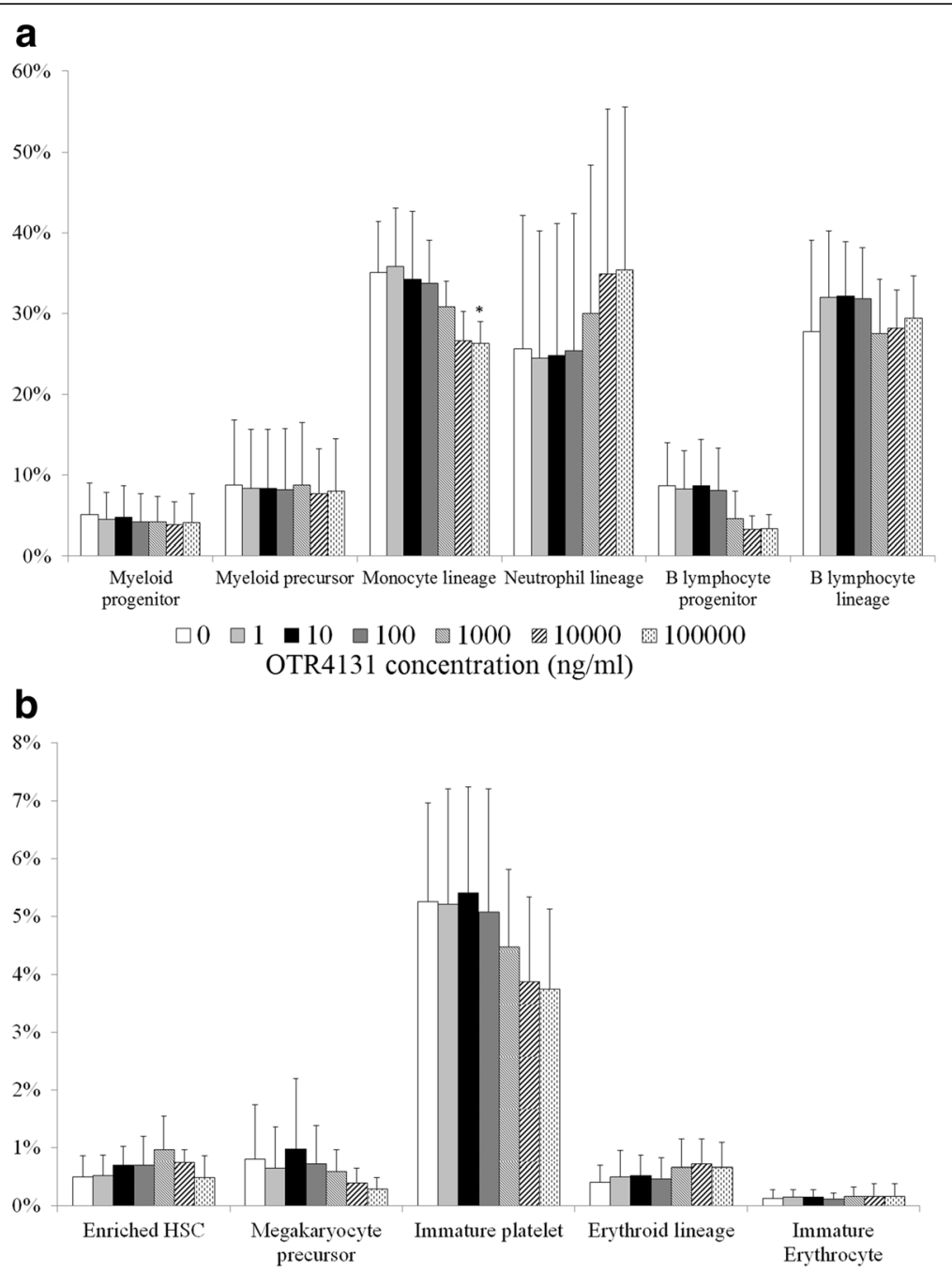

Fig. 2 Flow cytometry analyses of expanded HSPCs at day $12(n=4)$. a. Percentages of myeloid and lymphoid lineage after expansion. $\mathbf{b}$. Percentages of enriched HSC, megakaryocyte lineage and erythoid lineage after expansion. Each cell population was described following the cluster of differentiation presented in Table 1. ${ }^{*} p<0.05$. HSC hematopoietic stem cells

controls $(p=0.0038$ and $p=0.0120$, respectively, Fig. $3 \mathrm{~b})$. This effect was not observed when GAG mimetic was used at a concentration of $1 \mu \mathrm{g} / \mathrm{ml}$, for which HSPC migration was similar to that of controls.

\section{In vivo engraftment of expanded HSPCs}

Engraftment efficiency of expanded HSPCs and chimerism in mice hematopoietic organs were compared between controls and cells expanded with $1 \mu \mathrm{g} / \mathrm{ml}$ OTR4131. This concentration was chosen because $1 \mu \mathrm{g} /$ $\mathrm{ml}$ OTR4131did not affect the main tested parameters (amplification ratio, phenotype, migration, and clonogenicity) and tended to increase cell viability.

Data of bone marrow reconstitution 1 month after transplantation are summarized in Fig. 4. The percentages of chimerism $\left(\mathrm{CD} 45^{+}\right.$cells) were no different between controls $(1.6 \pm 0.5 \%)$ and $1 \mu \mathrm{g} / \mathrm{ml} \mathrm{OTR4131}$
$(2.3 \pm 1.0 \%)$ expanded HSPCs. However, HSPCs and HSCs (defined as CD $45^{+} / \mathrm{CD} 34^{\text {high }}$ cells) were lower in the OTR4131 group than in controls, with $5.6 \pm 1.9 \%$ vs. $10.8 \pm 2.6 \%(p=0.0174)$ and $1.7 \pm 1.0 \%$ vs. $4.1 \pm$ $1.1 \%(p=0.0181)$, respectively. No significant statistical differences were observed between the two groups regarding the various immature progenitors, such as multipotent progenitor cells, common myeloid progenitor cells, common lymphoid progenitor cells, megakaryocyte erythroid progenitor cells, and granulocyte macrophage progenitor cells. Similar results were obtained for lymphoid and megakaryocyte lineages. Some differences were obtained for myeloid lineage, however, with a decreased percentage of myeloid progenitors $\left(\mathrm{CD} 45^{+} /\right.$ $\left.\mathrm{CD} 34^{\text {high }} / \mathrm{CD} 3^{+}\right)$in the OTR4131 group $(14.7 \pm 9.4 \%)$ compared with controls $(36.2 \pm 5.2 \%)(p=0.0072)$, associated with an increased percentage of myeloid precursor 

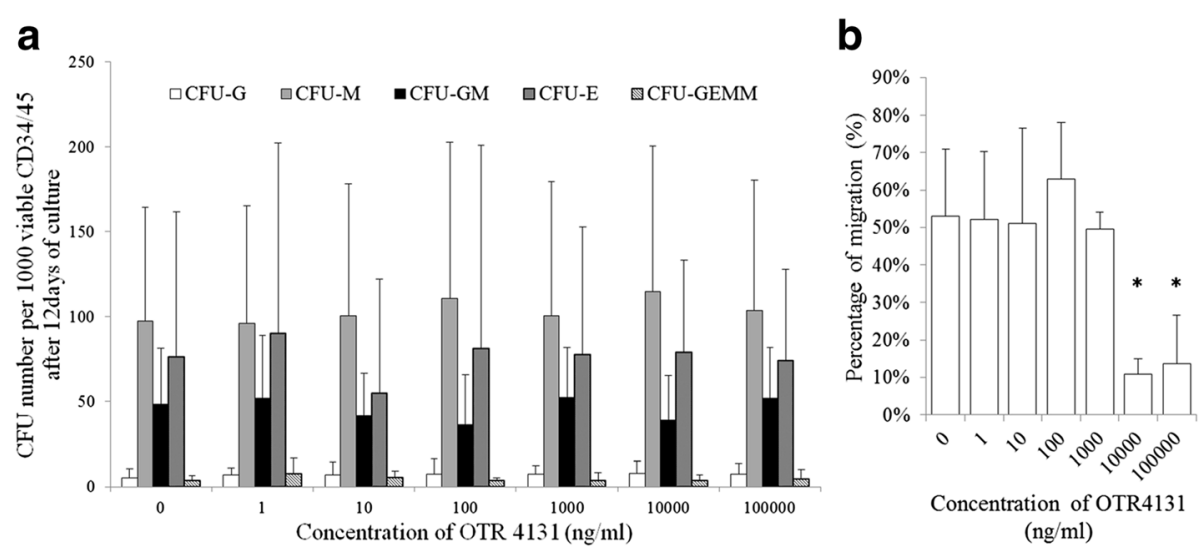

Fig. 3 In vitro functional properties of expanded cells. a Number of CFU-GEMM, CFU-E, CFU-G, CFU-M, and CFU-GM per 1000 viable CD34 /CD45 ${ }^{+}$cells $\left(n=4,{ }^{*} p<0.05\right)$. Error bars correspond to the standard deviation. $\mathbf{b}$ Migration capacity, expressed as the percentage of migration of total cells in front of a SDF-1 gradient ( $p=0.0038$ and $p=0.012$ respectively, $n=4)$. CFU-E colony-forming units of erythrocytes, CFU-G colony-forming units of granulocytes, CFU-GEMM colony-forming units of granulocytes, erythrocytes, monocytes, and megakaryocytes, CFU-GM colony-forming units of granulocytes and monocytes, CFU-M colony-forming units of monocytes

$\left(\mathrm{CD} 45^{+} / \mathrm{CD} 34^{\text {low }} / \mathrm{CD} 33^{+} / \mathrm{CD} 15^{+}\right): 56.3 \pm 15.5 \%$ and $23.1 \pm$ $8.1 \%$, respectively $(p=0.0080)$. Mature myeloid cell, neutrophil, and dendritic cell percentages were not modified, while monocytes were decreased in the OTR4131 group $(0.2 \pm 0.2 \%)$ compared with the control group $(0.8 \pm 0.2 \%)$ $(p=0.0077)$. Lastly, the erythroid lineage increased in the OTR4131 group, particularly for immature erythroid cells $\left(\mathrm{CD} 45^{-} / \mathrm{CD} 6^{+} / \mathrm{CD} 235^{+}\right)$, with percentages of $0.086 \pm$ $0.061 \%$ compared with $0.010 \pm 0.003 \%$ in the control group $(p=0.0477)$.

The bone marrow, thymus, and spleen chimerisms $\left(\mathrm{CD} 45^{+}\right.$cells) were analyzed in mice 3 months after expanded cell transplantation. No statistical difference was shown between controls and OTR4131 expanded cells, with a percentage of human cells of $5.8 \pm 5.4 \%$ vs. $15.0 \pm$ $10.1 \%$ in the bone marrow, of $21.2 \pm 36.0 \%$ vs. $11.7 \pm$ $6.6 \%$ in the thymus, and of $1.6 \pm 0.8 \%$ vs. $3.4 \pm 2.0 \%$ in the spleen, respectively. These results were consistent with similar percentages of hematopoietic lineages in the bone marrow in both groups (Fig. 4). Thymus and spleen explorations also showed that mice equally reconstitute progenitor and/or mature lineages (data not shown).

\section{Discussion}

Since the first definition of the stem cell niche introduced by Schofield [16], the knowledge of the microenvironment role toward hematopoiesis has evolved extensively. Cytokines and proteoglycans have been shown to play an important role in HSPC maintenance and differentiation. The role of proteoglycans has been extended to support endogenously expressed hematopoietic cytokines on the surface of stromal cells, in ECM, and in solution $[17,18]$. Moreover, a high fraction of total GAGs synthesized by stromal or hematopoietic cells is present in solution rather than on the stromal layer [19-21]. In the bone marrow niche, it is well known that GAGs play an important role in spatial organization and in interaction with hematopoietic cytokines $[6,7,22]$. For example, it was demonstrated that Glypican-3 proteoglycan is involved in HSC homing and maintenance mechanism, implicating interactions between the chemokine CXCL12 and its receptor CXCR4 [23]. Moreover, the relevance of GAG in the homeostasis of medullar microenvironment is attested by the demonstration that heparanase activity regulates retention and proliferation of primitive Sca-1/c$\mathrm{Kit} / \mathrm{Lin}^{-}$cells in mice bone marrow, whereas a reduction in the overall leukocyte cellularity bone marrow is observed. This suggests an important role of heparanase, and accordingly of HS, in hematopoietic progenitor cell regulation and control of the primitive cell pool size [24]. More recently, Saez et al. [25] demonstrated that inhibition of HS production in bone marrow osteolineage Mx1 stromal cells results in a disruption of HSC interactions within the niche and their egress into the peripheral circulation.

HSs, more particularly, are part of GAG subsets that can maintain HSPCs for in vitro long-term culture [18]. Several studies have also demonstrated an effect of heparin or noncharacterized human stromal-derived HS on different kinds of hematopoietic progenitors. Their presence during ex vivo amplification protocols has thus improved both megakaryocytic maturation and the amplification ratio [26-28]. For all these reasons, we hypothesized that OTR4131, a sulfated GAG mimetic, could have an interest in UCB HSPC amplification protocols.

These protocols were initially developed to overcome some limitations of UCB graft, such as delayed 

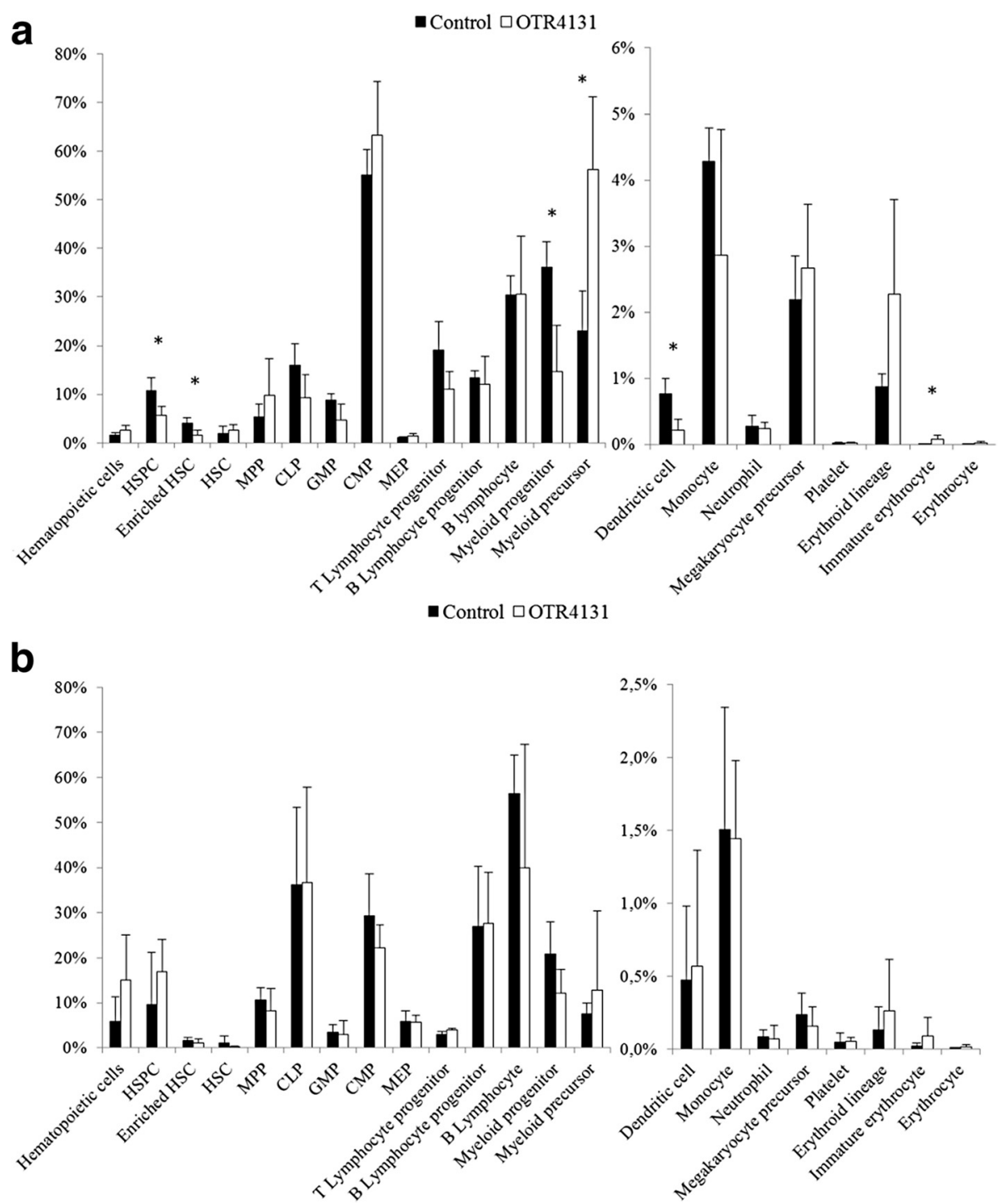

Fig. 4 Bone marrow NSG mice reconstitution after transplantation of expanded HSPCs. a One month after transplantation, human hematopoietic cells were characterized in mice bone marrow by flow cytometry. Cell markers are presented in Table $1(n=4) .{ }^{*} p<0.05$. b The same analyses were performed 3 months after transplantation $(n=3)$. CLP common lymphoid progenitor cells, CMP common myeloid progenitor cells, GMP granulocyte macrophage progenitor cells, hi high, HSC hematopoietic stem cells, HSPC hematopoietic stem cell and progenitor cell, lo low, MEP megakaryocyte erythroid progenitor cells, MPP multipotent progenitor cells

neutropenia and the need for transfusion caused by low number and immaturity of HSPCs $[1,2]$. According to the World Health Organization, more than 25 clinical trials have currently been initiated.

The present study deals with the GAG mimetic OTR4131, a well-characterized synthetic polymer RGTA $^{\circ}$. OTR4131 was here used for ex vivo amplification of UCB-derived HSPCs during 12 days. First of all, we observed an important interaction between fluorescent OTR4131 (at $10 \mu \mathrm{g} / \mathrm{ml}$ ) and HSPCs from 2 days of culture. Below this concentration, the fluorescent OTR4131 was not detectable with our fluorescent microscope. Concerning the amplification ratio, no difference was observed in the presence or absence of OTR4131, except for a better TNC viability at $1 \mu \mathrm{g} / \mathrm{ml}$ OTR4131. A similar increase of viability was observed on rat skin fibroblasts with $1 \mu \mathrm{g} / \mathrm{ml}$ OTR4120, another GAG mimetic compound. In this study, Yue et al. [29] concluded that this effect was related to a regulation of the premitochondrial death cascade with an inhibition of lysosomal cathepsin activities and a protection of the lysosome from membrane disruption. In that work, the RGTA $^{\circ}$ effect was associated with a reduction of intracellular reactive oxygen species levels and an 
inhibition of mitochondrial membrane potential collapse [29]. Moreover, we observed a decrease in the migration of amplified HSPCs with OTR4131, which could be explained by the elevated quantity of OTR4131 on the HSPC surface, blocking SDF-1 $\alpha$ chemoattraction by a sequestration effect [30]. Based on their phenotype or their clonogenic capacity, the composition of amplified HSPC populations was similar with or without OTR4131, except for an isolated decrease in monocyte lineage.

Furthermore, according to in vitro results of $1 \mu \mathrm{g} / \mathrm{ml}$ OTR4131 mimetic, the effect on NSG graft experiments was limited after 1 month: the different populations of HSPCs $\left(\mathrm{CD}_{3} 4^{+}\right.$or $\left.\mathrm{CD} 34^{\text {thigh }}\right)$ were statistically diminished in the OTR4131 group; and we observed an increase in the percentage of myeloid precursor cells and immature fraction of erythrocyte lineage. This modification was not stabilized in long-term graft whatever the lineage, and we therefore cannot conclude about a lasting change. These data suggest that GAGs probably impact cell differentiation at the level of long-term culture initiating cells (LTC-ICs) rather than at that of precursor or immature HSC. This hypothesis may also explain the modification observed on myeloid precursors, progenitors, and mature cells. These results are consistent with those already reported by Gupta et al. [17] during LTC-IC in vitro culture in the presence of various GAGs.

Even if the benefits of this specific mimetic on amplification protocols were too slight, however, we will discuss the interest of screening new compounds with more effective structural and functional features that would present an interest for in vitro or in vivo further uses. Accordingly, in the literature, GAG effects are linked to their structural signature. Gupta et al. $[17,18]$ compared the sulfatation profile of HS derived from a hematopoiesis supportive and nonsupportive cell line and found that a fine pattern of sulfate substitution is necessary to bind to hematopoietic cytokines such as interleukin-3, macrophage inflammatory protein-1 $\alpha$, and thrombospondin. Moreover, sulfatation pattern alteration has been found to reduce the ability of heparin, a more extensively sulfated form of HS, to maintain LTC-ICs [18, 31]. These structural characteristics provide specific binding properties to proteins. Thereby GAG-bind proteins are protected against proteases and interactions with their receptors are facilitated $[9,32,33]$. For example, fine characterization of the binding of heparin to G-CSF demonstrated the importance of sulfate groups since 2,3-O-sulfate groups are more important than $N$-sulfate groups in heparinG-CSF interaction [34]. Heparin-induced leukocytosis requires glucosamine 6-O-sulfation and is caused by blockade of L-selectin-mediated, P-selectin-mediated, and CXCL12-mediated leukocyte trafficking [35]. Finally, it was demonstrated that accumulated overly sulfated extracellular HS, in patients suffering from Mucopolysaccharidosis I, alters cytokine gradient formation since they abnormally bind and sequester CXCL12. This induces limited hematopoietic migration and engraftment, providing a potential mechanism for the limited scope of HSPC transplantation in Hurler syndrome [36].

\section{Conclusion}

Taking into consideration the development of ex vivo amplification UCB-derived HSPC strategy, the aim of this study was to potentiate a protocol based on a serum-free medium added with heparin-binding cytokines with a GAG mimetic named OTR4131. In our experimental conditions, GAG mimetic in medium during cell amplification seems not to be the best strategy. However, it could be interesting to design and screen several GAG mimetics with different sulfatation patterns that could be optimized to improve HSPC amplification.

\begin{abstract}
Abbreviations
$\mathrm{AF}^{647}$ : Alexa Fluor 647; CFU: Colony-forming unit; CFU-E: CFU of erythrocyte; CFU-G: CFU of granulocyte; CFU-GEMM: CFU of granulocyte, erythrocyte, monocyte, and megakaryocyte; CFU-GM: CFU of granulocyte and monocyte; CFU-M: CFU of monocyte; CS: Chondroitin sulfate; ECM: Extracellular matrix; GAG: Glycosaminoglycan; G-CSF: Granulocyte colony-stimulating factor; HS: Heparan sulfate; HSC: Hematopoietic stem cell; HSPC: Hematopoietic stem cell and progenitor cell; LTC-IC: Long-term culture initiating cell; NSG: NOD-scid/ $\mathrm{Yc}^{-/-}$; RGTA ${ }^{\oplus}$ : ReGeneraTing Agents ${ }^{\oplus}$; TNC: Total nucleated cells; UCB: Umbilical cord blood.
\end{abstract}

\section{Competing interests}

The authors declare that they have no competing interests.

\section{Authors' contributions}

LF contributed to conception and design, acquired, analyzed, and interpreted data, and wrote the manuscript. VP contributed to design the animal manipulation experiments and revised the manuscript. W, MG-S, FS, $\mathrm{PA}, \mathrm{SC}$, and $\mathrm{JL}$ contributed to the study design, analyzed the data, and revised the manuscript. All authors read and approved the manuscript.

\section{Acknowledgments}

The authors thank IUH Technological Platform for their help with flow cytometry: Niclas Setterblad, Christelle Doliger, Monique Cristofari, and Sophie Duchez. They thank Pr. D. Papy-Garcia for helpful readings of the manuscript. This work was supported by the association EGMOS (Entraide aux Greffés de Moelle Osseuse).

\section{Author details}

${ }^{1}$ Inserm, U 1160, Centre d'Investigation Clinique en Biothérapies, 75010 Paris, France. ${ }^{2}$ AP-HP, Hôpital Saint-Louis, Unité de Thérapie Cellulaire, Paris F-75010, France. ' ${ }^{3}$ épartement d'Expérimentation d'Animale, Université Paris Diderot, Institut Universitaire d'Hématologie, Hôpital Saint-Louis, Paris F-75010, France. ${ }^{4}$ OTR3 Company, 4 rue Française, 75001 Paris, France. ${ }^{5}$ Université Paris Est Créteil, Université Paris Est, EA 4397 ERL CNRS 9215, Laboratoire CRRET, 61 Avenue du Général de Gaulle, 94010 Créteil, France.

${ }^{6}$ Université Paris Diderot, Sorbonne Paris Cité, U 1160, Paris F-75010, France.

Received: 16 September 2015 Revised: 8 December 2015

Accepted: 18 December 2015 Published online: 07 January 2016

\section{References}

1. Cutler C, Ballen K. Improving outcomes in umbilical cord blood transplantation: state of the art. Blood Rev. 2012;26:241-6. 
2. Metheny L, Caimi $P$, de Lima M. Cord blood transplantation: can we make it better? Front Oncol. 2013;3:238.

3. Boiron JM, Dazey B, Cailliot C, Launay B, Attal M, Mazurier F, et al. Large-scale expansion and transplantation of CD34(+) hematopoietic cells: in vitro and in vivo confirmation of neutropenia abrogation related to the expansion process without impairment of the long-term engraftment capacity. Transfusion. 2006; 46:1934-42.

4. Csaszar E, Kirouac D, Yu M, Wang W, Qiao W, Cooke M, et al. Rapid expansion of human hematopoietic stem cells by automated control of inhibitory feedback signaling. Cell Stem Cell. 2012;10:218-29.

5. Duchez P, Chevaleyre J, Vlaski M, Dazey B, Milpied N, Boiron J, et al. Definitive setup of clinical scale procedure for ex vivo expansion of cord blood hematopoietic cells for transplantation. Cell Transplant. 2012;21:2517-21.

6. Coombe DR. The role of stromal cell heparan sulphate in regulating haemopoiesis. Leuk Lymphoma. 1996;21:399-406.

7. Klein $\mathrm{G}$. The extracellular matrix of the hematopoietic microenvironment. Experientia. 1995;51:914-26.

8. Morris AJ, Turnbull JE, Riley GP, Gordon MY, Gallagher JT. Production of heparan sulphate proteoglycans by human bone marrow stromal cells. J Cell Sci. 1991;99(Pt 1):149-56.

9. Xu D, Esko J. Demystifying heparan sulfate-protein interactions. Annu Rev Biochem. 2014:83:129-57.

10. Wegrowski Y, Milard AL, Kotlarz G, Toulmonde E, Maquart FX, Bernard J. Cell surface proteoglycan expression during maturation of human monocytes-derived dendritic cells and macrophages. Clin Exp Immunol. 2006;144:485-93.

11. Papy-Garcia D, Barbier-Chassefière V, Rouet V, Kerros M, Klochendler C, Tournaire $M$, et al. Nondegradative sulfation of polysaccharides. synthesis and structure characterization of biologically active heparan sulfate mimetics. Macromolecules. 2005;38:4647-54

12. Ikeda Y, Charef S, Ouidja M, Barbier-Chassefière V, Sineriz F, Duchesnay A, et al. Synthesis and biological activities of a library of glycosaminoglycans mimetic oligosaccharides. Biomaterials. 2011;32:769-76.

13. Albanese P, Caruelle D, Frescaline G, Delbé J, Petit-Cocault L, Huet E, et al. Glycosaminoglycan mimetics-induced mobilization of hematopoietic progenitors and stem cells into mouse peripheral blood: structure/function insights. Exp Hematol. 2009;37:1072-83.

14. Green D, Rubin C. Consequences of irradiation on bone and marrow phenotypes, and its relation to disruption of hematopoietic precursors. Bone. 2014;63:87-94

15. Ivanovic Z, Duchez P, Dazey B, Hermitte F, Lamrissi-Garcia I, Mazurier F, et al. A clinical-scale expansion of mobilized CD 34+ hematopoietic stem and progenitor cells by use of a new serum-free medium. Transfusion. 2006;46:126-31.

16. Schofield $\mathrm{R}$. The relationship between the spleen colony-forming cell and the haemopoietic stem cell. Blood Cells. 1978:4:7-25.

17. Gupta P, McCarthy JB, Verfaillie CM. Stromal fibroblast heparan sulfate is required for cytokine-mediated ex vivo maintenance of human long-term culture-initiating cells. Blood. 1996;87:3229-36.

18. Gupta P, Oegema TR, Brazil JJ, Dudek AZ, Slungaard A, Verfaillie CM. Structurally specific heparan sulfates support primitive human hematopoiesis by formation of a multimolecular stem cell niche. Blood. 1998;92:4641-51.

19. Wight TN, Kinsella MG, Keating A, Singer JW. Proteoglycans in human long-term bone marrow cultures: biochemical and ultrastructural analyses. Blood. 1986;67:1333-43.

20. Murali S, Manton K, Tjong V, Su X, Haupt L, Cool S, et al. Purification and characterization of heparan sulfate from human primary osteoblasts. J Cell Biochem. 2009;108:1132-42.

21. Minguell JJ, Tavassoli M. Proteoglycan synthesis by hematopoietic progenitor cells. Blood. 1989;73:1821-7.

22. Cheng C, Lee Y, Lin S, Huangfu W, Liu I. Cell-autonomous heparanase modulates self-renewal and migration in bone marrow-derived mesenchymal stem cells. J Biomed Sci. 2014;21:21.

23. Khurana S, Margamuljana L, Joseph C, Schouteden S, Buckley SM, Verfaillie CM. Glypican-3-mediated inhibition of CD26 by TFPI: a novel mechanism in hematopoietic stem cell homing and maintenance. Blood. 2013;121:2587-95.

24. Spiegel A, Zcharia E, Vagima Y, Itkin T, Kalinkovich A, Dar A, et al. Heparanase regulates retention and proliferation of primitive Sca-1+/c-Kit
+/Lin- cells via modulation of the bone marrow microenvironment. Blood. 2008:111:4934-43.

25. Saez B, Ferraro F, Yusuf R, Cook C, Yu V, Pardo-Saganta A, et al. Inhibiting stromal cell heparan sulfate synthesis improves stem cell mobilization and enables engraftment without cytotoxic conditioning. Blood. 2014;124:2937-47.

26. Bramono D, Rider D, Murali S, Nurcombe V, Cool S. The effect of human bone marrow stroma-derived heparan sulfate on the ex vivo expansion of human cord blood hematopoietic stem cells. Pharm Res. 2011;28:1385-94.

27. Maurer AM, Gezer A. Promoting effects of heparin on ex vivo expansion of megakaryocytopoiesis from human cord blood CD34+ cells. Transfus Med Hemotherapy. 2013:40:344-50.

28. Okamoto T, Takagi M, Soma T, Ogawa H, Kawakami M, Mukubo M, et al Effect of heparin addition on expansion of cord blood hematopoietic progenitor cells in three-dimensional coculture with stromal cells in nonwoven fabrics. J Artif Organs. 2004;7:194-202.

29. Yue XL, Lehri S, Li P, Barbier-Chassefière V, Petit E, Huang Q-F, et al. Insights on a new path of pre-mitochondrial apoptosis regulation by a glycosaminoglycan mimetic. Cell Death Differ. 2009;16:770-81.

30. Sadir R, Imberty A, Baleux F, Lortat-Jacob H. Heparan sulfate/heparin oligosaccharides protect stromal cell-derived factor-1 (SDF-1)/CXCL12 against proteolysis induced by CD26/dipeptidyl peptidase IV. J Biol Chem. 2004;279:43854-60.

31. Gupta P, Oegema TR, Brazil JJ, Dudek AZ, Slungaard A, Verfaillie CM. Human LTC-IC can be maintained for at least 5 weeks in vitro when interleukin-3 and a single chemokine are combined with O-sulfated heparan sulfates: requirement for optimal binding interactions of heparan sulfate with early-acting cytokines and matrix pr. Blood. 2000;95:147-55

32. Coombe DR. Biological implications of glycosaminoglycan interactions with haemopoietic cytokines. Immunol Cell Biol. 2008:86:598-607.

33. Coombe DR, Kett WC. Heparan sulfate-protein interactions: therapeutic potential through structure-function insights. Cell Mol Life Sci. 2005;62:410-24

34. Liang A, Liu X, Du Y, Wang K, Lin B. Further characterization of the binding of heparin to granulocyte colony-stimulating factor: importance of sulfate groups. Electrophoresis. 2008;29:1286-90.

35. Zhang S, Condac E, Qiu H, Jiang J, Gutierrez-Sanchez G, Bergmann C, et al. Heparin-induced leukocytosis requires 6-O-sulfation and is caused by blockade of selectin- and CXCL12 protein-mediated leukocyte trafficking in mice. J Biol Chem. 2012;287:5542-53.

36. Watson HA, Holley R, Langford-Smith K, Wilkinson F, van Kuppevelt T, Wynn $R$, et al. Heparan sulfate inhibits hematopoietic stem and progenitor cell migration and engraftment in Mucopolysaccharidosis-I. J Biol Chem. 2014;289(52):36194-203

\section{Submit your next manuscript to BioMed Central and we will help you at every step:}

- We accept pre-submission inquiries

- Our selector tool helps you to find the most relevant journal

- We provide round the clock customer support

- Convenient online submission

- Thorough peer review

- Inclusion in PubMed and all major indexing services

- Maximum visibility for your research

Submit your manuscript at www.biomedcentral.com/submit

) Biomed Central 